$$
\text { CONF- } 9410281--?
$$

\title{
A Phase 1 Trial of Intravenous Boronophenylalanine-fructose Complex in Patients with Glioblastoma Multiforme
}

Bergland $R^{1}$, Elowitz $E^{1}$, Coderre $J A^{2}$, Joel $D^{2}$, Chadha $M^{3}$

Departments of Neurosurgery ${ }^{1}$ and Radiation Oncology ${ }^{3}$, Beth Israel Medical Center, New York, NY

Medical Department ${ }^{2}$, Brookhaven National Laboratory, Upton. NY

Key -words: boron neutron capture therapy, boronophenylalanine

glioblastoma

biodistribution

craniotomy;

Fax: $212-420-2701$

This research was supported in part by the U.S. Department of Energy under Contract No. DE-ACO2-76CH00016.

\section{DISCLAIMER}

This report was prepared as an account of work sponsored by an agency of the United States Government. Neither the United States Government nor any agency thereof, nor any of their employees, makes any warranty, express or implied, or assumes any legal liability or responsibility for the accuracy, completeness, or usefulness of any information, apparatus, product, or process disclosed, or represents that its use would not infringe privately owned rights. Reference herein to any specific commercial product, process, or service by trade name, trademark, manufacturer, or otherwise does not necessarily constitute or imply its endorsement, recommendation, or favoring by the United States Government or any agency thereof. The views and opinions of authors expressed herein do not necessarily state or reflect those of the United States Government or any agency thereof.

\section{MASTER}

DISTRIBUTION OF THIS DOCUMENT IS UNLLMTED 
A Phase 1 Trial of Intravenous Boronophenylalanine-fructose Complex in Patients with Glioblastoma Multiforme

Bergland $R^{1}$, Elowitz $E^{\top}$, Coderre $J A^{2}$, Joel $D^{2}$, Chadha $M^{3}$

Departments of Neurosurgery ${ }^{1}$ and Radiation Oncology ${ }^{3}$, Beth Israel Medical Center, New York, NY

Medical Department ${ }^{2}$, Brookhaven National Laboratory, Upton. NY

\section{INTRODUCTION}

Boron neutron capture therapy (BNCT) of glioblastoma multiforme was initially performed at the Brookhaven National Laboratory in the early 1950's'. While this treatment for malignant brain tumors has continued in Japan ${ }^{2}$, new worldwide interest has been stimulated by the development of new and more selective boron compounds. Boronophenylalanine (BPA) is a blood-brain barrier penetrating compound that has been used in BNCT of malignant melanomas ${ }^{3}$. BPA has been employed experimentally in BNCT of rat gliosarcoma ${ }^{4}$ and has potential use in the treatment of human glioblastoma. As a preface to clinical BNCT trials, we studied the biodistribution of BPA in patients with glioblastoma.

\section{METHODS}

Patients were selected for the study if they were undergoing craniotomy for resection of suspected glioblastoma based on MRI scan. Blood chemistries, including renal and liver profiles, were required to be in the normal range. Appropriate informed consent was obtained. Two to three hours prior to the start of surgery an intravenous infusion of BPA-fructose complex (100-170 $\mathrm{mg} / \mathrm{kg}$ ) was administered. Vital signs, including arterial blood pressure and cardiac monitoring, were followed during and after the infusion. Frequent blood samples were drawn to monitor blood boron levels for $\mathbf{4 8}$ hours after the start of the infusion. Urine was also collected over this same time period.

At surgery, multiple samples of tumor were obtained. An effort was made to sample various areas of the glioblastomas. Specimens of surrounding normal brain, scalp, muscle and dura were also sent for boron analysis. Separate 


\section{DISCLAIMER}

Portions of this document may be illegible in electronic image products. Images are produced from the best available original document. 


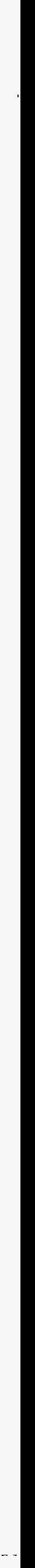


histopathologic examination was determined on all tumor samples obtained. Post-operatively, liver, renal and hematologic blood analyses were performed.

\section{RESULTS}

Seven patients were studied, all with histologically confirmed glioblastomas. Five patients were administered BPA-fructose at $130 \mathrm{mg} / \mathrm{kg}$ infusion and one patient each at $100 \mathrm{mg} / \mathrm{kg}$ and $170 \mathrm{mg} / \mathrm{kg}$. No adverse effects on vital signs or blood chemistries were seen.

The blood values (Fig 1) demonstrate a peaking of blood boron concentration at the end of the two hour infusion (the patient given $100 \mathrm{mg} / \mathrm{kg}$ was infused for only 1.5 hours) with a biphasic clearance of BPA. The blood curves appear to scale linearly with the different infusion doses of BPA.

Figure 1.

Figure 1. Boron concentrations following a 2 hour intravenous infusion of BPAfructose complex. Five patients were administered BPA-fructose at $130 \mathrm{mg} / \mathrm{kg}$ and one patient each at $100 \mathrm{mg} / \mathrm{kg}$ and $170 \mathrm{mg} / \mathrm{kg}$.

Multiple samples of scalp were obtained from the patients over the course of the surgery. Scalp boron concentrations were approximately 1.2-1.4 times those in blood (Fig 2). These scalp to blood ratios are similar to those described in skin. ${ }^{5}$

Figure 2.

Figure 2. Scalp biopsy boron concentrations following BPA-fructose infusion (100-130 mg/ $\mathrm{kg}$ dose). The blood curve for the patients administered $130 \mathrm{mg} / \mathrm{kg}$ is shown for comparison. Multiple scalp samples were obtained from each patient.

Variability in boron concentrations both between tumor samples and between patients was observed (Fig 3). In most patients, tumor boron concentrations were higher than concentrations in adjacent brain samples. Peak tumor boron concentrations were $11-26 \mu \mathrm{g} / \mathrm{gm}$ while brain boron concentrations ranged from 3-10 $\mu \mathrm{g} / \mathrm{gm}$. 
Figure 3.

Figure 3. Boron concentrations in tumor and brain samples following BPAfructose infusion (100-130 mg/kg dose). for each of the seven patients.

Histologic examination of glioblastomas revealed regional variable degrees of cellularity and necrosis. Tumor samples from the more cellular areas had higher boron uptake than necrotic regions (Fig 4).

Figure 4.

Figure 4. Gadolinium-enhanced T1-weighted MRI image of Patient 6 (administered BPA-fructose $100 \mathrm{mg} / \mathrm{kg}$ ) with corresponding boron concentrations in cellular and necrotic regions of glioblastoma. The boron concentrations for scalp, muscle and adjacent brain are included.

\section{CONCLUSIONS}

1) BPA-fructose infusions $(100-170 \mathrm{mg} / \mathrm{kg}$ ) were well tolerated.

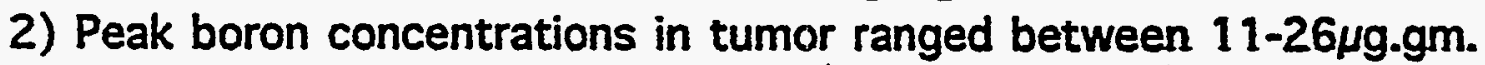

3) Variability in BPA uptake from tumor to tumor and within the same tumor can be explained, in part $r$ by the degree of regional cellularity and necrosis.

\section{REFERENCES}

1. L.E. Farr, W.H. Sweet, J.S. Robertson, C.G. Foster, H.B. Locksley, D.L. Suntherland, M.L. Mendelsohn and E.E. Stickly, Neutron capture therapy with boron in the treatment of glioblastoma multiforme. Am. J. Roentgenol. 71:279-291, 1954.

2. H. Hatanaka and Y. Nakagawa, Clinical results of long-surviving brain tumor patients who underwent boron neutron capture therapy. Int. J. Radiat. Oncol. Biol. Phys. 28:1061-1066, 1994.

3. Y. Mishima, C. Honda, M. Ichihashi, H. Obara, J. Hiratsuka, H. Fukuda, H. Karashima, T. Kobayashi, K. Kanda and K. Yoshino, Treatment of malignant melanoma by single thermal neutron capture therapy with melanoma-seeking $10_{B}$ compound. Lancet 12:388-389, 1989. 


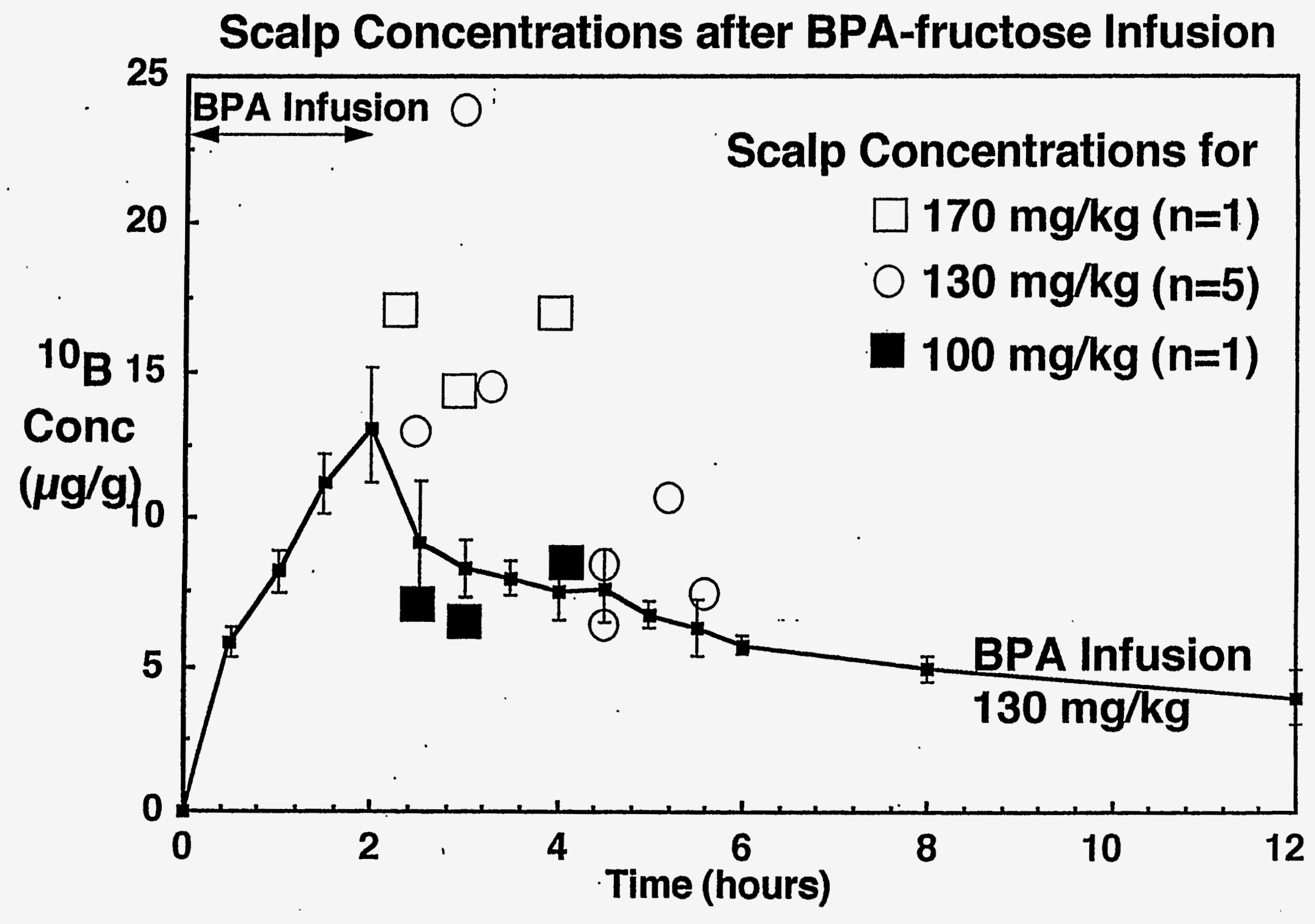




\section{Tumor and Brain Concentrations after BPA-fructose Infusion}

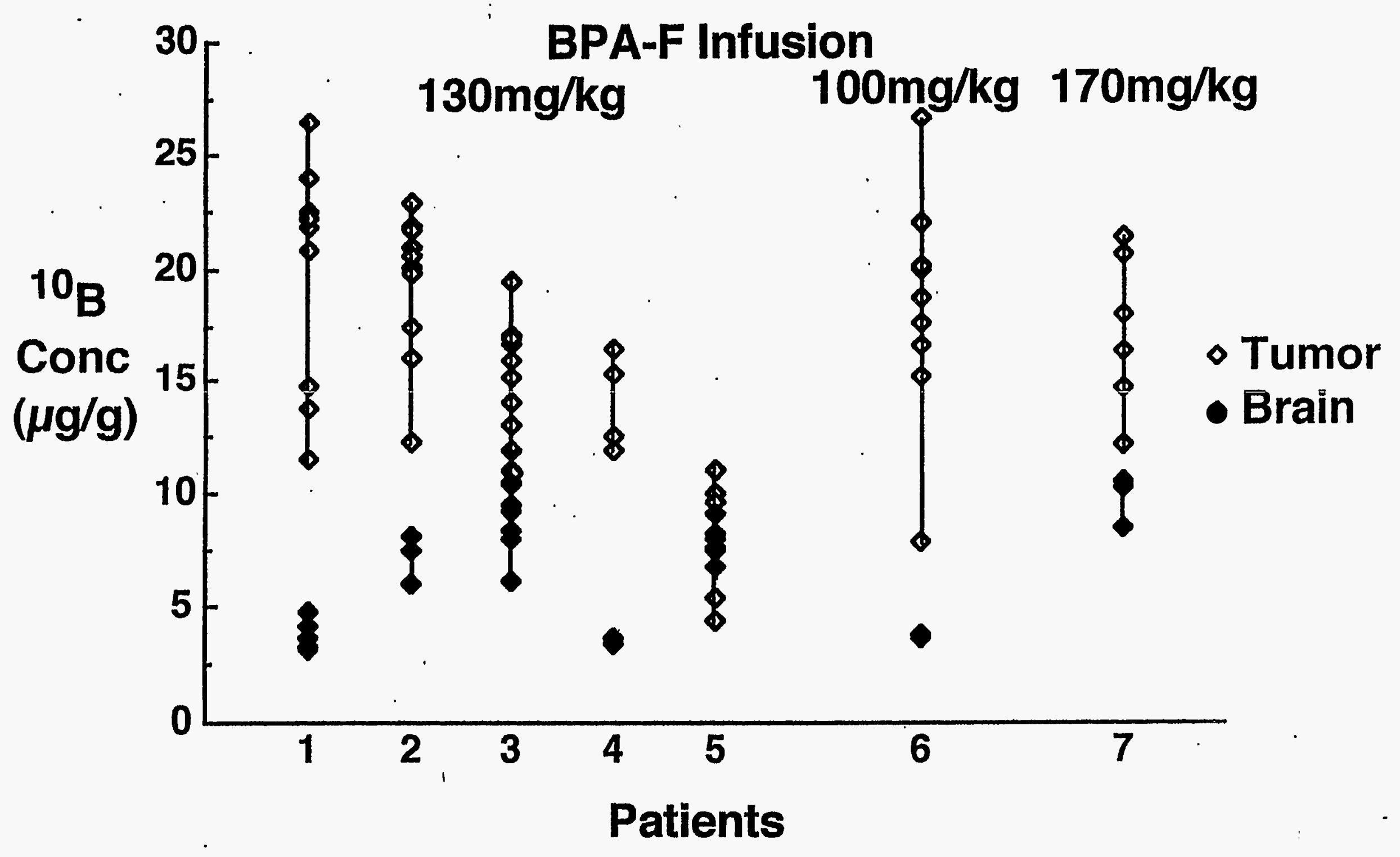




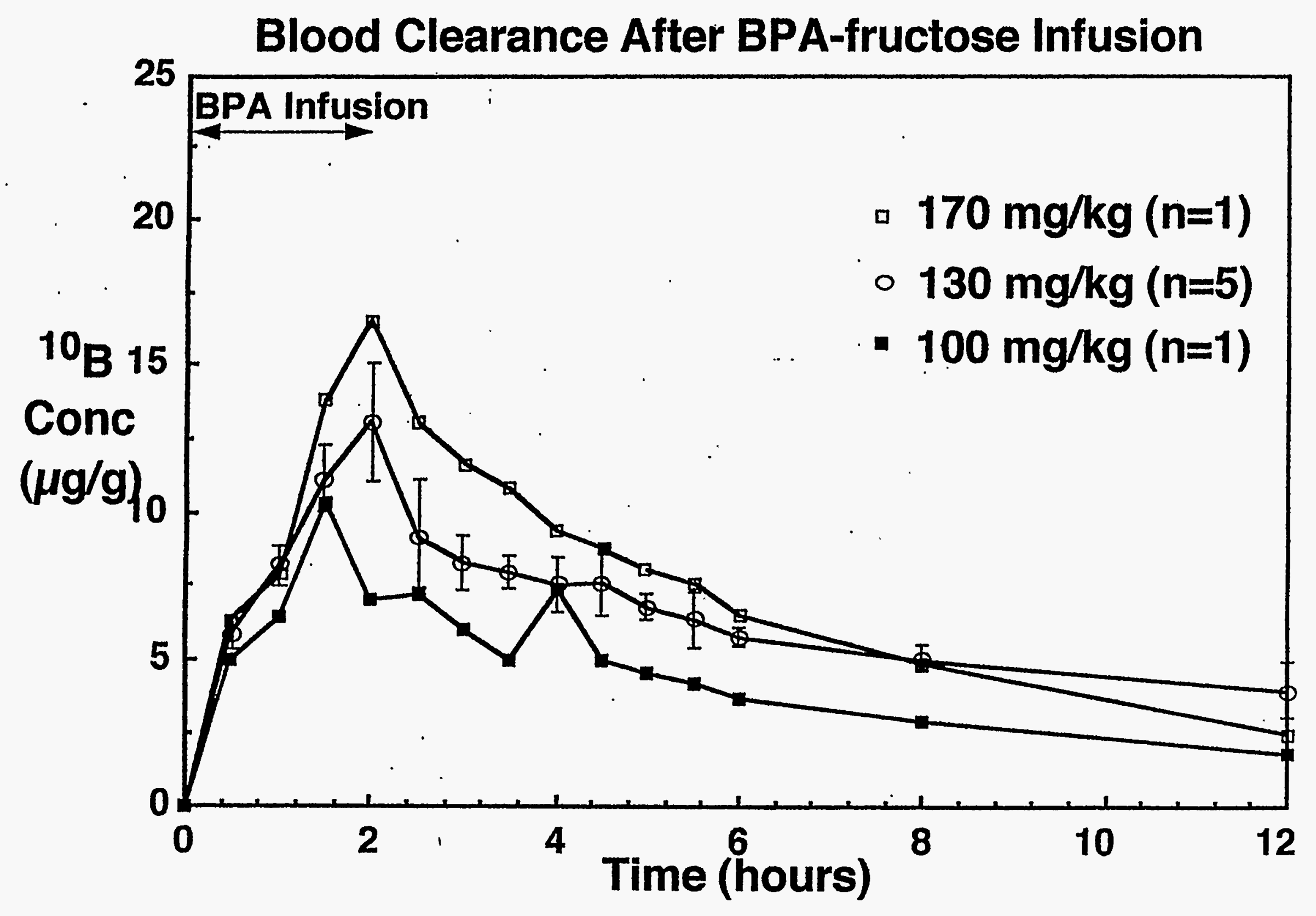




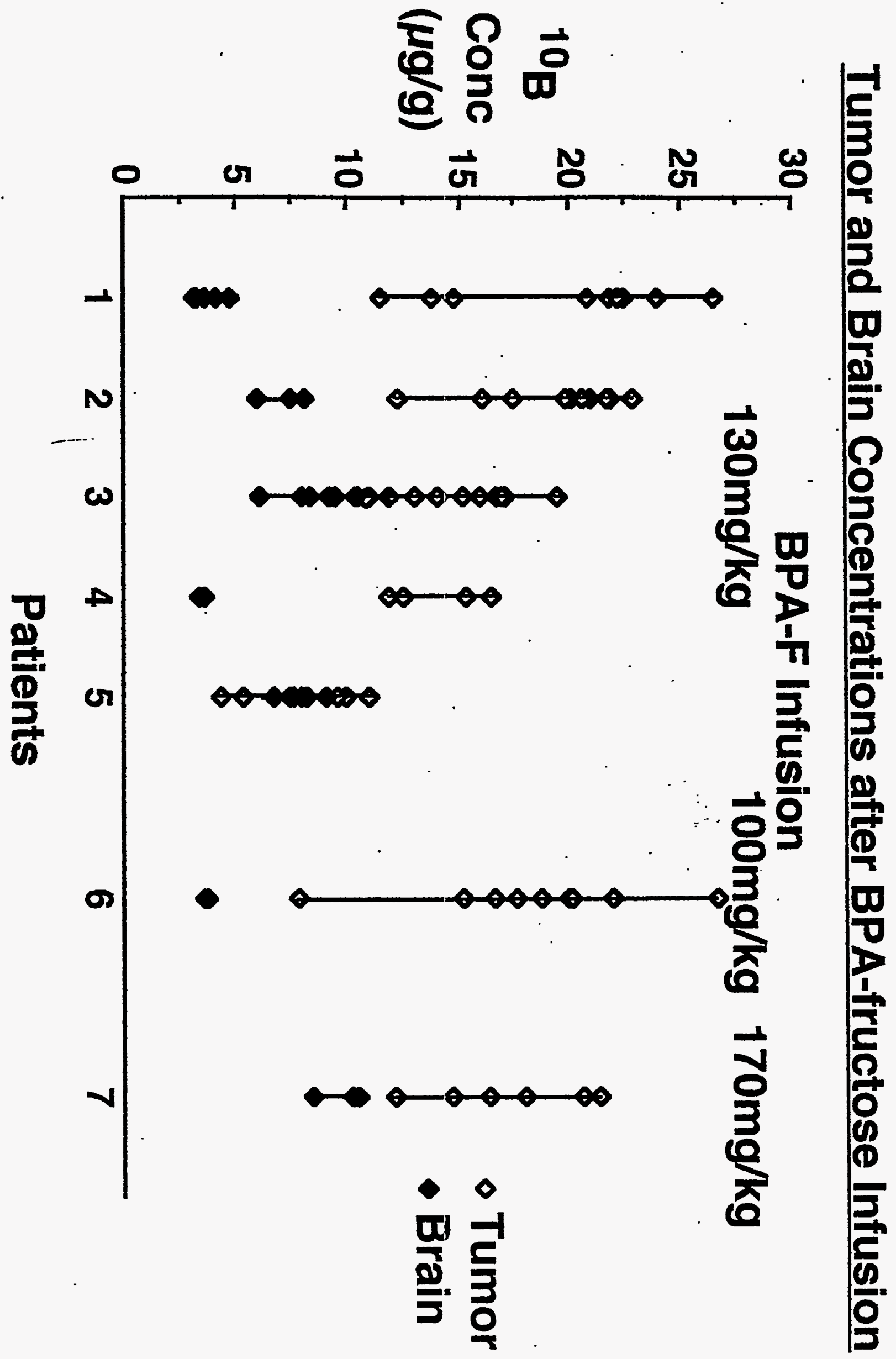

